\title{
Mr. Mustache and Friends: A Song Animation Video Development Based on Signalong Indonesia
}

\author{
Mudjito \\ Universitas Negeri Surabaya \\ Surabaya, Indonesia \\ mudjitomudjito@unesa.ac.id
}

\author{
Citra Fitri Kholidya \\ Universitas Negeri Surabaya \\ Surabaya, Indonesia \\ citrakholidya@unesa.ac.id
}

\author{
Khofidotur Rofiah \\ Universitas Negeri Surabaya \\ Surabaya, Indonesia \\ khofidoturrofiah@unesa.ac.id
}

\begin{abstract}
This research aims to produce a prototype of Signalong Indonesia based children's song animation video media for children with special needs as a solution for children with special needs in delays or communication constraints. Signalong media as a medium to facilitate the communication style of each individual. Moreover, Signalong Indonesia helps the understanding and interaction of children with special needs in communicating with others, teachers, parents or the surrounding community. Mr. Mustache and Friends this can provide effective and inclusive educational shows with animated videos for all people, especially Indonesian children. This study uses a Research and Development development model with the following development procedures. The results of this research and development are in the form of a prototype of an animated video media that has gone through a feasibility test in the form of a validation test, a media expert, a material expert, a product trial and a product revision stage so that the media is included in the appropriate category of use.
\end{abstract}

Keywords-signalong Indonesia; mr mustache and friends; song animation video, childern with special seeds, inclusive school, $R \& D$ model

\section{INTRODUCTION}

Communication of children with special needs has different characteristics in how to communicate [1], [2]. Communication characteristics of children with special needs who experience obstacles in communication barriers, how to communicate using sign language, on motor barriers how to communicate using symbol communication media, and on intellectual barriers how to communicate using symbols [3]. Children with special needs need more media to communicate. The media can be in the form of signs and symbols.

Conditions such as those described above have been more than five years in the UK have been carried out in-depth studies and solutions to overcome these problems by optimizing sign communication skills so that all children with special needs more easily understand communication messages. Signalong Indonesia's communication is already in the form of a dictionary but is more effective if it is developed in the form of a themed video making it easier for children with special needs, parents and the community, in general, can learn easily so as to overcome communication barriers [4], [5]

The purpose of this research is to develop animated videothemed through Indonesian children's songs. Because learning songs is easier and more fun[6]. The urgency of developing animated videos; (1) facilitating the communication style of each individual, (2) Signalong Indonesia help understanding and interacting children with special needs in communicating with others, teachers, parents or with the surrounding community, ( $3 \mathrm{Mr}$. Mustache and Friends program can provide effective and inclusive educational shows with animated videos for all people, especially Indonesian children. This animated video media has specifications shown in Table 1.

TABLE I. PRODUCT SPECIFICATION

\begin{tabular}{|c|l|l|}
\hline No & \multicolumn{1}{|c|}{ Product } & \multicolumn{1}{c|}{ Specification } \\
\hline \multirow{5}{*}{1} & \multirow{2}{*}{$\begin{array}{l}\text { Animation } \\
\text { Video }\end{array}$} & $\begin{array}{l}\text { 1. This animated video is conceptualized } \\
\text { in the form of a children's song with an } \\
\text { animated mustache pack with a theme of } \\
\text { everyday life played by a model that } \\
\text { exhibits signalong }\end{array}$ \\
\cline { 3 - 4 } & $\begin{array}{l}\text { 2. This animated video was developed } \\
\text { with supporting software including Adobe } \\
\text { Photoshop, Corel Draw X7. Processing } \\
\text { images with Adobe after effect CS6, } \\
\text { Adobe Audition CS6 for audio, Adobe } \\
\text { premiere to unify animation and audio. }\end{array}$ \\
\hline \multirow{2}{*}{2} & Manual Book & 1. Guidelines for using media \\
\cline { 3 - 4 } & & 2. Children's songs \\
\cline { 3 - 4 } & & 3. Media care instructions \\
\hline
\end{tabular}




\section{MethODS}

\section{A. Research Type}

This research using research development with the approach of Research and Development (R\&D) [7]. Research and development or R\&D methods are research methods used to produce certain products and test the feasibility of those products. This research will produce a product in the form of Children's Song Animation Video based on Signalong Indonesia as communication for children with special needs.

\section{B. Development Procedure}

Figure 1 adaptation of the step model of the educational research approach and development of Borg and Gall [8]

The stages of research are as follows:

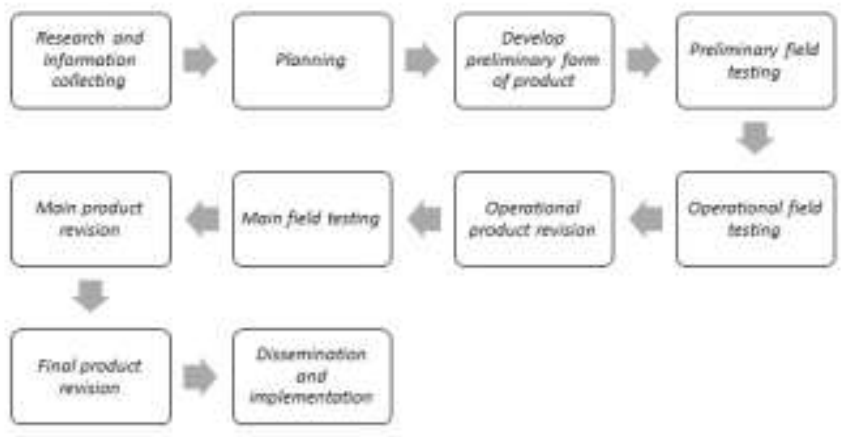

Fig. 1. The research stages

\section{Potential and Problem}

At this stage, the researchers conducted a preliminary study in the form of an analysis of the needs of the target. The problem faced by children with special needs in communication is that children have difficulty in understanding and interacting with others. The potential is the Indonesian signalong dictionary.

\section{Data Collection}

The data collection stage is more specific on mapping words in the Signalong Indonesian dictionary to specific themes and songs that are appropriate.

\section{Product Design}

The design stage starts from creating a Media Content Outline, Program Content Outline, story board and an Indonesian signalong based video animation song script, talent determination, video shooting and developing animation.

\section{Design Validation}

At this stage the researcher validates the media expert regarding the compatibility of the media with the developed text. Next to the material experts regard the suitability of the content with the media.

For the content validity of the product will be validated by Prof Kieron Sheehy from Open University UK, He is a
Signalong expertise who always focus on this topic in his research.

\section{Design Revision}

Design revisions are made if there is input from media experts and experts on signalong video-based media animation materials

\section{Product trials}

Product trials are carried out to the target of children with special needs at the Galuh Handayani foundation as partners in individual trials and small group trials. There are 66 students with different grades and different disabilities.

\section{Product Revision}

The revision stage is carried out on the results of input from media and material experts and the results of trials by the target

\section{Usage Test}

The usage test is the implementation phase of the use of video media by all targets

\section{Product Revision}

After the trial use, a revision is made if there are inputs and suggestions from the product trial results.

\section{Mass production}

The production was not carried out in this study only until the due diligence test because the animation video media was limited to the prototype of the Indonesian children's song animated video media prototype.

\section{Data analysis}

\section{Qualitative Descriptive}

Specific qualitative data analysis is performed on the suggestions and comments of the evaluators (experts and product users). Qualitative data are presented transparently as consideration for revising and perfecting video animation media

\section{Descriptive Statistical Analysi}

Descriptive statistical analysis is used to process the data obtained in the form of percentage analysis. Percentage techniques are used to present data that are the frequency with which subjects respond to the product that has been developed. The analysis technique used to process data [9], [10], namely: $100 \%$

$\mathrm{P}=$ (number of answer scores $) /(\mathrm{n} \times$ highest weight $) \mathrm{x}$

Next to calculate the percentage of the whole subject try using the percentage formula. This percentage technique is used to present data that are the frequency of responses of test subjects to teaching material products. The formula used is:

$$
\mathrm{P}=\mathrm{F} / \mathrm{N}
$$


Note: $\mathrm{P}=$ Percentage

$\mathrm{F}=$ Total percentage of the whole subject

$\mathrm{N}=$ Total number of test subjects

Decision making on medical qualification level is used qualification with the following eligibility criteria shown in Table 2.

TABLE II. THE CRITERIA RANGE

\begin{tabular}{|l|l|l|l|}
\hline No & Range & \multicolumn{1}{|c|}{ Criteria } & \multicolumn{1}{|c|}{ Qualification } \\
\hline 1 & $81 \%-100 \%$ & Very Good & Very Decent \\
\hline 2 & $61 \%-80 \%$ & Well & Worthy Decent \\
\hline 3 & $41 \%-60 \%$ & Enough & Enough \\
\hline 4 & $21 \%-40 \%$ & Less & Inadequate \\
\hline 5 & $0 \%-20 \%$ & Very Less & Not Feasible \\
\hline
\end{tabular}

\section{RESUlTS AND DISCUSSION}

\section{A. Signalong Indonesia}

Signalong is a signaling system that helps children gain language skills and to improve communication skills [5], [11]. Signalong Indonesia is a sign system based on Indonesian culture that is used for children with special needs for special and inclusive schools to improve communication and quality of learning (Signalong Indonesia).

Signalong Indonesia's symbol is a symbol in the form of images made based on the characteristics of children with special needs and Indonesian culture to help children acquire language skills, improve communication skills and as visual communication for signalong signals in Indonesia [4], [5].

The basic concept of Signalong is based on British Sign Language (BSL). Almost all signs of BSL have not changed. There are some gestures that have been adjusted for ease of use and some have been generated where there are appropriate British Sign Language cues to be found [12], [13]. Signalong is committed to empowering children and adults with communication disorders to understand and express their needs, choices, and desires by providing a vocabulary for life and learning. Signs are always used with spoken words to help children focus on information that carries words in a sentence and help them to understand the main point of the message

The basic concept of Signalong Indonesia is to develop patterns of oral communication in the right learning process so that it is easily understood by children with special needs in special schools and inclusive schools. not all children with special needs have the ability to use oral communication properly, so they cannot take lessons well [14], [15]. Therefore signalong system communication model is adopted and adapted to the conditions and culture of Indonesian communication so that it can be implemented in an effort to improve the quality of education services especially for children with special needs.

\section{B. Mr. Mustache and Friends as a Communication Strategies for Children with Special Needs}

Communication means the process of delivering a statement by one person to another person as a consequence of social relations. The communication contains a specific purpose, namely to inform (informative) or to change attitudes, opinions, or behavior (persuasive), both directly through verbal (verbal) or indirectly through the media (non-verbal), namely through writing or gesture [1].

Basically, communication is very important for humans, because human communication can create a relationship with other people and establish good socialization with people around him [17]. Communication is divided into verbal communication (words) and non-verbal communication (body language).

Non-verbal communication is "exchanging messages by not using words, eye contact, facial expressions, closeness, distance, and touch". Nonverbal communication is communication that uses gestures, such as nodding, flashing, shaking his head, etc. Verbal and non-verbal communication are interrelated and complement each other in the communication that we do every day [3], [18].

Characteristics of communication in children with special needs who experience hearing and communication (hearing impairment) is the way to communicate using sign language, for the finger alphabet has been patented internationally while for sign language varies in each country. Total communication is a way of communicating by involving verbal language, sign language, and body language. Deaf individuals tend to have difficulty understanding the concept of something abstract [19].

In understanding culture, it must refer to a number of cultural characteristics, including that culture is shared, obtained through learning, is symbolic, is adaptive, is relative and universal [20]. A communication system is a group of elements or people who have guidelines and media that carry out an activity of managing, storing, issuing ideas, ideas, symbols, and symbols that make messages in making decisions to reach an agreement and mutual understanding with each other with processing the message into a source of information.

As a component of communication culture in Indonesia, nonverbal expressions have much in common with language. Both are encoding systems or signals that are learned and passed down as part of cultural experience. Non-verbal symbols and the responses generated by these symbols are part of the cultural experience passed on from one generation to another. Each symbol has a different meaning because people have different experiences about the symbol [21]. Culture influences and directs these experiences, and therefore culture also influences and directs a person about how to send, receive, and respond to these nonverbal symbols. For example, in Indonesia if you say no by saying the signal "shake your head", for the symbol or symbol in Indonesia symbolizes a picture of a mother with the picture "Mother wearing a bun". 


\section{CONCLUSION}

Communication for children with disabilities must design an appropriate strategy to archive the goal. Mr. Mustache and Friends are the modified models to encourage children to have a better communication system by using Signalong Indonesia.

\section{ACKNOWLEDGMENT}

The authors would like to thank the participants of this study for their valuable contribution. Also, special thanks give to Universitas Negeri Surabaya, Indonesia which funded and supported to conduct this research.

\section{REFERENCES}

[1] W. Bank, Globalization, growth, and poverty : building an inclusive world economy. 2002.

[2] R. Horton-Ikard, M. L. Munoz, S. Thomas-Tate, and Y. Keller-Bell, "Establishing a Pedagogical Framework for the Multicultural Course in Communication Sciences and Disorders," Am. J. SpeechLanguage Pathol., vol. 18, no. 2, pp. 192-206, 2009.

[3] E. Purbaningrum and K. Rofiah, "The Impact of Language Skills Guidance on Children With Hearing Impairment Language Development," vol. 212, pp. 503-506, 2018.

[4] K. Sheehy, Budiyanto, H. Kaye, and K. Rofiah, "Indonesian teachers' epistemological beliefs and inclusive education," $J$. Intellect. Disabil., vol. 23, no. 1, pp. 39-56, 2019.

[5] K. Sheehy, "Developing Signalong Indonesia: issues of politics, pedagogy, and perceptions," 2019.

6] G. Knowles, Supporting Inclusive Practice, Second Edition. 2018

[7] R. C. Bogdan and S. K. Biklen, "Qualitative research for education: An introduction to theories and methods. Uttar Pradesh." India: Pearson India Education Services Pvt. Ltd, CIN, 2016.

[8] M. D. Gall, W. R. Borg, and J. P. Gall, Educational research: An introduction. Longman Publishing, 1996.

[9] S. N. Calculator and T. Black, "Validation of an Inventory of Best Practices in the Provision of Augmentative and Alternative Communication Services to Students With Severe Disabilities in General Education Classrooms," Am. J. Speech-Language Pathol., vol. 18 , no. 4, pp. 329-342, 2009.

[10] C. Opie and P. J. Sikes, Doing educational research. Sage, 2004

[11] G. Kennard, T. Grove, and L. Hall, Signalong:(Basic Vocabulary). Phase 3. Signalong Group, 1997.

[12] G. Richards, Teaching and Learning in Diverse and Inclusive Classrooms. 2016.

[13] K. Rofiah, F. Ardianingsih, I. K. Ainin, and M. Sujarwanto, “Are Indonesian Sign Language and Total Communication Beneficial for Teachers in Inclusive School?,” vol. 272, pp. 203-206, 2018.

[14] V. Cooper, "Blocks to learning: How Signalong helped establish effective communication with her son Daniel, opening the way to learning in other fields," Spec. Child., pp. 24-27, 1996.

[15] L. Cook, "Actions speak louder than words: introducing Signalong to young people with Autistic Spectrum Disorder as a tool for enhancing understanding of higher-level emotion vocabulary," 2011.

[16] Budiyanto, K. Sheehy, H. Kaye, and K. Rofiah, "Developing Signalong Indonesia: issues of happiness and pedagogy, training and stigmatization," Int. J. Incl. Educ., vol. 22, no. 5, pp. 543-559, 2018

[17] M. Langevin, A. Packman, and M. Onslow, "Peer Responses to Stuttering in the Preschool Setting," Am. J. Speech-Language Pathol., vol. 18, no. 3, pp. 264-276, 2009.

[18] D. F. Loeb, R. B. Gillam, L. Hoffman, J. Brandel, and J. Marquis, "The Effects of Fast ForWord Language on the Phonemic Awareness and Reading Skills of School-Age Children With Language Impairments and Poor Reading Skills," Am. J. SpeechLanguage Pathol., vol. 18, no. 4, pp. 376-387, 2009.

[19] P. Buhere, J. Ndiku, and J. Kindiki, "Inclusive Education and School Culture: Integration Issues for Mainstream Primary Schools in Kenya," Int. J. Educ. Res., vol. 2, no. 5, pp. 423-432, 2014.
"Challenges Facing Implementation of Inclusive Education in Public Primary Schools in Nyeri Town, Nyeri County, Kenya," vol. 5, no. 16, pp. 118-125, 2014.

[21] D. Youdell, Impossible bodies impossible selves. 2006 